TI 2003-028/2

Tinbergen Institute Discussion Paper

Valuing Euro Rating-Triggered

Step-Up Telecom Bonds

\author{
Patrick Houweling ${ }^{1,2}$ \\ Albert Mentink ${ }^{1,3}$ \\ Ton Vorst ${ }^{1,2,4}$
}

${ }^{7}$ Erasmus University Rotterdam, 2 Tinbergen Institute, ${ }^{3}$ AECON Asset Management, ${ }^{4}$ ABN Amro. 


\section{Tinbergen Institute}

The Tinbergen Institute is the institute for economic research of the Erasmus Universiteit Rotterdam, Universiteit van Amsterdam, and Vrije Universiteit Amsterdam.

Tinbergen Institute Amsterdam

Roetersstraat 31

1018 WB Amsterdam

The Netherlands

Tel.: $\quad+31(0) 205513500$

Fax: $\quad+31(0) 205513555$

Tinbergen Institute Rotterdam

Burg. Oudlaan 50

3062 PA Rotterdam

The Netherlands

Tel.: $\quad+31(0) 104088900$

Fax: $\quad+31(0) 104089031$

Please send questions and/or remarks of nonscientific nature to driessen@tinbergen.nl.

Most TI discussion papers can be downloaded at http://www.tinbergen.nl. 


\title{
Valuing Euro Rating-Triggered Step-Up Telecom Bonds ${ }^{1}$
}

\author{
Patrick Houweling ${ }^{2}$
}

Erasmus University Rotterdam

\author{
Albert Mentink ${ }^{3}$ \\ Erasmus University Rotterdam and AEGON Asset Management
}

\section{Ton Vorst ${ }^{4}$}

Erasmus University Rotterdam and ABN Amro

February 6, 2003

\footnotetext{
${ }^{1}$ The authors thank Arjan van Dijk, Martijn Krijger and Joost Kromhout for computational assistance. Views expressed in the paper are the authors' own and do not necessarily reflect those of AEGON Asset Management or ABN Amro.

${ }^{2}$ P.O. Box 1738, 3000 DR Rotterdam, The Netherlands; tel: +31-10-408.1244; fax: +31-10-408.9162; e-mail: houweling@few.eur.nl

${ }^{3}$ Corresponding author. P.O. Box 903, 2501 CX, The Hague, The Netherlands; tel: +31-70-344.8177; e-mail: amentink@aegon.nl

${ }^{4}$ P.O. Box 1738, 3000 DR Rotterdam, The Netherlands; tel: +31-10-408.1270; fax: +31-10-408.9162; e-mail: vorst@few.eur.nl
} 


\section{Valuing Euro Rating-Triggered Step-Up Telecom Bonds}

We value rating-triggered step-up bonds with three methods: (i) the Jarrow, Lando and Turnbull [1997, JLT] framework, $(i i)$ a similar framework using historical probabilities and (iii) as plain vanilla bonds. We find that the market seems to value single step-up bonds according to the JLT model, while it values multiple step-up bonds as plain vanilla bonds. Further, step-up feature market premiums are more volatile than JLT and historical premiums, and the JLT model approximates market premiums always better than the historical method. Finally, most step-up bonds offer a cushion against rating migrations via dampened price movements. 


\section{Introduction}

European telecom companies have issued rating-triggered step-up coupon bonds in order to compensate bond investors for losses in the event of rating downgrades. Several investment banks (McAdie, Martin and O'Kane [2000], Fumagalli and Tauren [2001] and Sirinathsingh [2001]) analyzed step-up bonds. Most of the time, they used historical and subjective rating transition probabilities in their step-up valuation and showed the results of their model for only one day. In contrast, we apply the risk-neutral valuation framework of Jarrow, Lando and Turnbull [1997, hereafter JLT] to value the step-up bonds and demonstrate the model's results over a long time period. For comparison purposes, we also value step-up bonds using historical transition probabilities and as equivalent plain vanilla bonds, i.e. bonds similar to step-up bonds

except for the step-up feature. Moreover, we analyze the protection that the step-up feature offers to investors in two ways new to the literature. First, we test the volatility of a step-up bond versus its equivalent plain vanilla bond. Second, we determine whether the step-up bond offers superior returns over its equivalent plain vanilla bond in case of rating downgrades and negative outlooks.

Our results indicate that the market seems to use the JLT model to value step-up bonds that make a single step-up after the rating trigger. On the other hand, step-up bonds that make multiple step-ups seem to be treated as plain vanilla bonds. Also, the JLT model approximates the step-up feature premium always better than the historical method. We further find that the step-up feature reduces bond price volatility for most of the considered step-up bonds. Finally, for all bonds in our sample, the step-up feature does not offer investors positive excess returns in case of a rating downgrade or a change to negative outlook.

The coupon of a step-up bond depends on its issuer's rating or the rating of the issuer's long term debt. If this rating deteriorates and hits a predefined level, the step-up feature is triggered and the coupon rises with a predefined number of basis points. Depending on the 
exact specification of the step-up language, the coupon can rise even more if the rating further deteriorates. For most step-up bonds, the reverse also applies, i.e. the coupon is reduced if the rating increases again. Step-up bonds are a relatively new phenomenon in the euro-denominated corporate bond market. Both issuers and investors benefit from this step-up feature, see McAdie et al. [2000]. Issuers have placed a larger volume of debt at lower prices than would otherwise have prevailed. Investors have profited as well, because they will be compensated in the event of rating downgrades and because issuers should be more committed to their rating as a downgrade will penalize them directly by higher coupon payments.

We analyze five step-up bonds that have been issued by three companies: Deutsche Telecom, France Telecom and KPN. These are the only three companies in our data set that have issued both step-up bonds and enough euro-denominated plain vanilla bonds to reliably estimate issuerspecific interest rate curves. Even though we can analyze only a limited number of step-up bonds, this study is worthwhile, because it provides one of the first empirical tests of the JLT model on rating-sensitive instruments and because the behaviour of step-up bonds has not yet been documented in the acadamic literature.

Various investment banks have published about the characteristics and valuation of stepup bonds, for example Lehman Brothers [McAdie et al., 2000], J.P. Morgan [Sirinathsingh, 2001], Schroder Salomon Smith Barney [Fumagalli and Tauren, 2001] and Société General [Turc, 2001]. J.P. Morgan used historical transition and default probabilities in their valuation; Lehman Brothers estimated these probabilities subjectively by using their analysts' opinions; Schroder Salomon Smith Barney applied both subjective and historical transition probabilities; Société General implemented a JLT-type of model and used risk-neutral probabilities. These papers all showed the results of their analysis for only one day. In contrast, we price the step-up bonds for a longer period, i.e. March 2001 - February 2002, and implement three pricing methods.

Despite the large interest from practitioners, only one academic paper [Conroy, 2000] has been 
published about the valuation of euro step-up bonds, as far as we know. Like most investment banks, Conroy also valued step-up bonds using historical rating transition probabilities. Riskneutral valuation models that can be used to price rating-triggered instruments have appeared in the academic literature though. The basis for most of these models is the JLT Markov chain model, which uses a firm's credit ratings as an indicator of the likelihood of default. Kijima and Komoribayashi [1998] adjusted the JLT model to make it numerically more stable by replacing default probabilities with survival probabilities in the calculation of risk premia. The JLT model has been generalized by Das and Tufano [1996] to incorporate stochastic recovery rates, and by Lando [1998] and Arvanitis, Gregory and Laurent [1999] to make transition and default intensities stochastic and possibly dependent on state variables. Bielecki and Rutkowski [2000] and Acharya, Das and Sundaram [2002] embedded the Markov chain in a Heath, Jarrow and Morton [1992] framework with stochastic forward rates. Acharya et al. [2002] also provided an illustration of their model on a stylized step-up bond.

The content of the rest of this paper is the following. First, we describe the characteristics of step-up bonds in Section 2. Next, in Section 3, the JLT model is briefly summarized and the risk-neutral valuation of step-up bonds is explained. Further, we describe the valuation methods using historical probabilities and as equivalent plain vanilla bonds. Section 4 describes our data set. The results of applying the three valuation methods to the data are given in Section 5 . We also test whether including step-up features offers the investor sufficient protection using both volatility tests and we conduct an event study on rating and outlook changes. Finally, Section 6 summarizes.

\section{Step-Up Bonds}

The coupon of a step-up bond depends on the issuer's rating or the rating of its long term debt. If the rating deteriorates and hits a predefined level, the step-up coupon is triggered and the 
coupon rises with a predefined number of basis points. Depending on the step-up coupon type, the coupon can rise even more if the issuer's rating further deteriorates. For most step-up bonds, the reverse also applies, i.e. the coupon is reduced if the rating improves again. This is called the step-down feature. The coupon can never go below the original level at issuance though.

Step-up coupon bond conditions can differ between issuers. Also, a single company can issue different types of step-up bonds. The most important discriminating conditions of the step-up bonds are the following: whether the coupon can step up and down or only steps up, whether both Moody's and S\&P have to downgrade the issuer or only one of them before the step-up trigger is hit, the timing of the coupon adjustment, the rating-trigger level and the number of basis points (bps) of the step-up. Based on McAdie et al. [2000] and Marchakitus, Soderberg and Bramley [2001], we define three types of step-up bonds using these conditions, see Table 1.

[Insert Table 1 around here]

\section{Model}

\subsection{Rating Transitions}

The value of a step-up bond equals the sum of the discounted, expected cash flows as for any other bond. However, unlike plain vanilla bonds, their coupons are a function of the issuer's rating and therefore we have to model the issuer's rating transition process under the equivalent martingale measure. The JLT model provides a suitable framework for this purpose, since it uses a company's credit rating as an indicator of that company's creditworthiness.

We follow the setup of the JLT model. We assume that a unique equivalent martingale measure $\tilde{\mathbb{Q}}$ exists that makes all default-free and defaultable bond prices martingales, after normalization by the default-free money-market account. Further, under $\tilde{\mathbb{Q}}$, default-free interest rates and the default time $\tau$ are independent. Finally, the recovery rate $\delta$ is constant; we follow 
Jarrow and Turnbull [2000] and Schönbucher [2000] by assuming that $\delta$ applies to the principal only, not to the coupons.

The company's credit rating $R_{t}$ at day $t$ is modelled as a Markov chain on a finite state space $S=\{1, \ldots, K\}$ under the historical probability measure. The state space $S$ contains all possible ratings, including the minor ratings: state 1 represents the Aaa rating, state 2 Aa1, state $3 \mathrm{Aa} 2, \ldots$, state $K-1 \mathrm{Caa}$, and the last state, $K$, default. It is assumed that default is an absorbing state. Under the Markov property, it holds for all $i, j \in S, t \geq s \geq 0$ and $r_{u} \in S$, $0 \leq u<s$ that

$$
\begin{aligned}
q_{i j}(s, t) & =\mathbb{P}\left(R_{t}=j \mid R_{s}=i, R_{u}=r_{u}, 0 \leq u<s\right) \\
& =\mathbb{P}\left(R_{t}=j \mid R_{s}=i\right),
\end{aligned}
$$

i.e. the probability of going from rating $i$ to rating $j$ in the period from $s$ to $t$ only depends on the rating $R_{s}$ at time $s$ and not on the history $R_{u}, 0 \leq u<s$, of reaching that rating. We are aware of the limitations of this assumption, as past rating movements do seem to affect future rating transitions, as shown by Nagpal and Bahar [2000]; however, it is an assumption common to most theoretical models.

In order to value step-up bonds, we need the rating transition process under the risk-neutral measure $\tilde{\mathbb{Q}}$. JLT started with the observed, historical transition probabilities, for example from a rating transition matrix from Moody's or $\mathrm{S} \& \mathrm{P}$, and applied risk premia to transform these into risk-neutral probabilities. We choose to adjust the $(T-t)$-year transition matrix ${ }^{1} Q(t, T)$ to get the risk-neutral transition matrix $\tilde{Q}(t, T)$ as follows

$$
\tilde{q}_{i j}(t, T)= \begin{cases}\pi(t, T) q_{i j}(t, T) & \text { for } j \neq K \\ 1-\pi(t, T)\left(1-q_{i K}(t, T)\right) & \text { for } j=K\end{cases}
$$


for some risk premium $\pi(t, T)$. It follows that the risk premium can be calculated as

$$
\pi(t, T)=\frac{1-\tilde{q}_{R_{t}, K}(t, T)}{1-q_{R_{t}, K}(t, T)}
$$

The risk premium for time $T$ is the ratio of the risk-neutral survival probability to the historical survival probability, so that we retain the numerical stability of Kijima and Komoribayashi [1998, hereafter KK]. Note that we use 'cumulative' probabilities $\tilde{q}_{i j}(t, T)$ instead of JLT's and KK's 'forward' probabilities $\tilde{q}_{i j}(t, t+1)$, i.e.

$$
\tilde{q}_{i j}(t, t+1)=\pi_{i}(t, t+1) q_{i j}(t, t+1) .
$$

The advantage of our risk premia is that their calculation is easier, because they do not require matrix inversion, cf. JLT's formula (16) and KK's formula (19). Both approaches, 'forward' and 'cumulative', generate the same results though. Also, note that we only use one risk premium for all rating categories. Ideally, we would like to use a separate risk premium for all ratings. However, each euro-denominated telecom issuer does not cover the full rating spectrum, so that we have to resort to one risk premium, derived from the issuer's current rating, and apply it to all ratings.

For each day, we estimate the issuer-specific survival probability curve of each telecom company. Following Houweling and Vorst [2002, Section 4], we specify a linear hazard function, assume a recovery rate of $50 \%$, and use the euro zero-coupon swap curve as proxy for the default-free term structure. The parameters of the hazard function are estimated on the market prices of that issuer's plain vanilla bonds using non-linear least squares. Given the estimated survival probability curve for a company on a particular day, we calculate its risk premia (2) and risk-neutral transition matrices (1) for all required maturities. These risk-neutral matrices are used to calculate theoretical values for step-up bonds using the methods of the next section. We 
also calculate $95 \%$ confidence bounds for the survival probability curve, and repeat this series of calculations for the upper and lower bound, hence obtaining upper and lower bounds for the step-up bond values as well.

\subsection{Step-Up Valuation}

To determine the theoretical value of a defaultable step-up and step-down bond, we add the following assumption to the set of JLT assumptions mentioned in the previous section: both Moody's and S\&P alter their rating of an issuer at the same time. ${ }^{2}$ In Section 4 , we show that this is a plausible assumption to make. In our analysis, we apply the Moody's rating actions. In the remainder of this section, we discuss our three methods to value step-up bonds, starting with the JLT model.

Consider a step-up and step-down bond with $n$ remaining coupon payments and a face value of 1 . The bond issuer makes the $j^{\text {th }}$ coupon payment at day $t_{j}, j=1,2, \ldots, n$, but only if he has not gone into default before $t_{j}$. If the rating at $t_{j-1}$ is equal to $r$, the coupon payment at $t_{j}$ is equal to $c_{r}, r=1, \ldots, K$. The coupon payment at $t_{1}$ depends on the rating at $t_{0}$, which we define as the previous coupon date, or, if there is no previous coupon, the issue date. The step-up bond's principal amount is paid at maturity $t_{n}$, again only if the issuer has not defaulted before $t_{n}$. In case the issuer does default before the bond matures, the constant recovery rate $\delta$ of the notional is paid at the default time. Applying the risk-neutral valuation principle to these coupon, principal and recovery cash flows, yields

$$
\begin{aligned}
B^{J L T}(t, \mathbf{t}, \mathbf{c})= & \sum_{j=1}^{n} p\left(t, t_{j}\right) \tilde{\mathbb{E}}_{t}\left[\mathbf{1}_{\left\{\tau>t_{j}\right\}} c_{R_{t_{j-1}}}\right]+ \\
& p\left(t, t_{n}\right) \tilde{\mathbb{E}}_{t}\left[\mathbf{1}_{\left\{\tau>t_{n}\right\}}\right]+ \\
& \tilde{\mathbb{E}}_{t}\left[p(t, \tau) \mathbf{1}_{\left\{\tau \leq t_{n}\right\}} \delta\right]
\end{aligned}
$$

where $\mathbf{t}$ is an $n$-vector with the coupon payment dates, $\mathbf{c}$ is a $K$-vector with the coupon per- 
centages per rating category, $p(t, T)$ denotes the time- $t$ default-free discount factor for time $T$, $\tilde{\mathbb{E}}_{t}[X]$ denotes the $\tilde{\mathbb{Q}}$-expected value of $X$ given the information at day $t$ and $\mathbf{1}_{\{A\}}$ is the indicator function of event $A$. The first line of (3) contains the coupon payments, the second line the principal payment, and the last line the potential recovery payment.

The first risk-neutral expectation in (3) can be evaluated as follows: for $j>1$, we have ${ }^{3}$

$$
\begin{aligned}
\tilde{\mathbb{E}}_{t}\left[\mathbf{1}_{\left\{\tau>t_{j}\right\}} c_{R_{t_{j-1}}}\right] & =\sum_{k=1}^{K} \tilde{\mathbb{P}}_{t}\left(\tau>t_{j} \wedge R_{t_{j-1}}=k\right) c_{k} \\
& =\sum_{k=1}^{K} \tilde{\mathbb{P}}_{t}\left(\tau>t_{j} \mid R_{t_{j-1}}=k\right) \tilde{\mathbb{P}}_{t}\left(R_{t_{j-1}}=k\right) c_{k} \\
& =\sum_{k=1}^{K} \tilde{q}_{R_{t}, k}\left(t, t_{j-1}\right)\left(1-\tilde{q}_{k, K}\left(t_{j-1}, t_{j}\right)\right) c_{k},
\end{aligned}
$$

where $\tilde{\mathbb{P}}_{t}(A)$ denotes the risk-neutral probability of event $A$ given the information at day $t$; for $j=1$, the coupon amount is already known (because $R_{t_{0}}$ is already known), so the expectation reduces to

$$
\tilde{\mathbb{E}}_{t}\left[\mathbf{1}_{\left\{\tau>t_{1}\right\}} c_{R_{t_{0}}}\right]=\tilde{\mathbb{P}}_{t}\left(\tau>t_{1}\right) c_{R_{t_{0}}}=\left(1-\tilde{q}_{R_{t}, K}\left(t, t_{1}\right)\right) c_{R_{t_{0}}}
$$

After evaluating the second and third risk-neutral expectations in (3) too, the JLT value of our rating-triggered step-up and step-down bond equals

$$
\begin{aligned}
B^{J L T}(t, \mathbf{t}, \mathbf{c})= & p\left(t, t_{1}\right)\left(1-\tilde{q}_{R_{t}, K}\left(t, t_{1}\right)\right) c_{R_{t_{0}}}+ \\
& \sum_{j=2}^{n}\left[p\left(t, t_{j}\right) \sum_{k=1}^{K} \tilde{q}_{R_{t}, k}\left(t, t_{j-1}\right)\left(1-\tilde{q}_{k, K}\left(t_{j-1}, t_{j}\right)\right) c_{k}\right]+ \\
& p\left(t, t_{n}\right)\left(1-\tilde{q}_{R_{t}, K}\left(t, t_{n}\right)\right)+ \\
& \sum_{j=1}^{n} p\left(t, t_{j}\right)\left(\tilde{q}_{R_{t}, K}\left(t, t_{j}\right)-\tilde{q}_{R_{t}, K}\left(t, t_{j-1}\right)\right) \delta
\end{aligned}
$$

where we follow Houweling and Vorst [2002] by replacing the integral that results from the 
recovery payment with a numerical approximation with potential default dates equal to the coupon payment dates. Note that the only difference between Equation (4) and the value of a plain vanilla $(\mathrm{PV})$ bond,

$$
\begin{aligned}
B^{P V}(t, \mathbf{t}, c)= & \sum_{j=1}^{n} p\left(t, t_{j}\right)\left(1-\tilde{q}_{R_{t}, K}\left(t, t_{j}\right)\right) c+ \\
& p\left(t, t_{n}\right)\left(1-\tilde{q}_{R_{t}, K}\left(t, t_{n}\right)\right)+ \\
& \sum_{j=1}^{n} p\left(t, t_{j}\right)\left(\tilde{q}_{R_{t}, K}\left(t, t_{j}\right)-\tilde{q}_{R_{t}, K}\left(t, t_{j-1}\right)\right) \delta,
\end{aligned}
$$

is the part relating to the specific coupon structure of the step-up bond. If we set $c_{k}=c$ for all $k$, the expected value of the $j^{\text {th }}$ coupon payment reduces to that of a plain vanilla bond

$$
\begin{aligned}
\sum_{k=1}^{K} \tilde{q}_{R_{t}, k}\left(t, t_{j-1}\right)\left(1-\tilde{q}_{k, K}\left(t_{j-1}, t_{j}\right)\right) c & =c\left(\sum_{k=1}^{K} \tilde{q}_{R_{t}, k}\left(t, t_{j-1}\right)-\sum_{k=1}^{K} \tilde{q}_{R_{t}, k}\left(t, t_{j-1}\right) \tilde{q}_{k, K}\left(t_{j-1}, t_{j}\right)\right) \\
& =c\left(1-\tilde{\mathbb{P}}_{t}\left(R_{t_{j}}=K\right)\right) \\
& =c\left(1-\tilde{q}_{R_{t}, K}\left(t, t_{j}\right)\right) .
\end{aligned}
$$

As a second valuation method, we treat the step-up bond as a bond that is identical except for the step-up feature. We refer to this bond as the equivalent plain vanilla bond. Just like the step-up bond, the first coupon of this bond also depends on the rating at $t_{0}$, but the remaining coupons are assumed to follow from the current rating, i.e. they are all equal to $c_{R_{t}}$. The value of the equivalent plain vanilla (EPV) bond thus equals

$$
\begin{aligned}
B^{E P V}(t, \mathbf{t}, \mathbf{c})= & p\left(t, t_{1}\right)\left(1-\tilde{q}_{R_{t}, K}\left(t, t_{1}\right)\right) c_{R_{t_{0}}}+ \\
& \sum_{j=2}^{n} p\left(t, t_{j}\right)\left(1-\tilde{q}_{R_{t}, K}\left(t, t_{j}\right)\right) c_{R_{t}}+ \\
& p\left(t, t_{n}\right)\left(1-\tilde{q}_{R_{t}, K}\left(t, t_{n}\right)\right)+ \\
& \sum_{j=1}^{n} p\left(t, t_{j}\right)\left(\tilde{q}_{R_{t}, K}\left(t, t_{j}\right)-\tilde{q}_{R_{t}, K}\left(t, t_{j-1}\right)\right) \delta .
\end{aligned}
$$


The difference with the JLT formula (4) is the second line, which no longer includes a summation over possible future ratings, but instead assumes the current rating $R_{t}$ will prevail. The EPV formula also strongly resembles the PV formula (5), except that the first coupon may differ from the other coupons.

The third method we consider to value step-up bonds, the historical valuation method, is based on the methods investment banks often applied, e.g. McAdie et al. [2000] and Fumagalli and Tauren [2001]. This method uses the telecom company's zero-coupon curve to discount expected coupons, where the expectation is calculated with historical transition probabilities rather than risk-neutral probabilities; again, the first coupon is known. This gives

$$
B^{H}(t, \mathbf{t}, \mathbf{c})=v\left(t, t_{1}\right) c_{R_{t_{0}}}+\sum_{j=2}^{n}\left[v\left(t, t_{j}\right) \sum_{k=1}^{K} q_{R_{t}, k}\left(t, t_{j-1}\right) c_{k}\right]+v\left(t, t_{n}\right),
$$

where $v(t, T)$ denotes the issuer's time- $t$ discount factor for time $T$.

\section{Data}

Most euro-denominated step-up bonds have been issued by telecom companies. Analyzing these rating-triggered step-up corporate bonds thus automatically means focusing on the telecom sector. Step-up bonds are an important source of financing for telecom companies, because at the end of March 2001, step-up bonds accounted for $42 \%$ of the market capitalization of the telecom bond market [Fumagalli and Tauren, 2001]. We analyze the set of euro-denominated step-up coupon telecom bonds as listed by both Lehman Brothers [McAdie et al., 2000] and J.P. Morgan [Marchakitus et al., 2001]. For these European telecom companies, we download the main characteristics and the price time series for all their bonds from Bloomberg on a daily basis for the period 4 January 1999 - 13 February 2002. We use the Bloomberg Generic (BGN) price. 
The BGN price is an average of prices that are quoted by a long list of banks and brokers and reflects the bid side of London closing. BGN prices are also used to price the Bloomberg/EFFAS government bond indices [Brown, 1994].

We make sure that the bonds used in the curve estimation are plain vanilla. We classify a bond as a plain vanilla bond if the bond has no step-up language, no embedded options, is not floating and not convertible. From the downloaded prices, we remove quotes that equal the quote of the preceding day(s) and quote spikes. We seldom have to remove quotes though. Table 2 shows the number of all euro-(re)denominated bonds, plain vanilla bonds and euro-denominated step-up coupon bonds of the telecom companies that have issued step-up bonds. Three issuers, Deutsche Telecom, France Telecom and KPN, have a large number of quoted, plain vanilla bonds compared to the other telecom companies, British Telecom, Olivetti/Tecnost and Telecom Italia. In our analyses, we focus on the step-up bonds of the first three issuers only, because we need to estimate issuer-specific survival probability curves as described in Section 3 and this curve estimation requires a certain number of plain vanilla bonds. These three companies are large corporate bond issuers as they together represent $6.5 \%$ of the Lehman Brothers Euro-Aggregate Corporate Bond Index on 31 May 2002.

[Insert Table 2 around here]

Table 3 displays the characteristics of the step-up bonds we will use in our analysis: the step-up type, as defined in Table 1, the number of basis points step-up $X$ and the rating-trigger level $Y$. We restrict ourselves to step-up bonds with step-up and step-down coupons, because from our three telecom issuers just one KPN bond has step-up only language. Valuing a step-up only bond, type C in Table 1, differs from a bond with step-up and step-down features, types A and B in Table 1, because the coupon of a step-up only bond is path-dependent. This means that if the rating at any time before the coupon date has been below the trigger-level the coupon payment includes the step-up, even after the issuer is upgraded to or even above the pre step- 
up rating again; this path-dependency characteristic necessitates an other valuation procedure than Equation (4). In short, once triggered, a step-up only bond becomes a plain vanilla bond. This is exactly what happened to the KPN step-up only bond seven months after its issuance. Therefore, from the first coupon date after this rating event, we treat it as a plain vanilla bond and use it in our estimation of the KPN curve.

[Insert Table 3 around here]

We download the Moody's and Standard \& Poor's rating and outlook history of Deutsche Telecom, France Telecom and KPN from Bloomberg as well. From Moody's, we use the issuer's rating and from $\mathrm{S} \& \mathrm{P}$ the rating of long term debt in local currency. Figure 1 shows the rating and outlook migrations of Deutsche Telecom by both Moody's and S\&P's for the sample period. A negative (positive) outlook is denoted by the $-(+)$ sign. Figures 2 and 3 contain the same information for France Telecom and KPN, respectively. These three figures show that the rating dynamics of both rating agencies are very similar. At the end of our period the two agencies assign identical ratings to each of our three telecom companies. We believe that these figures justify our additional modelling assumption in Section 3.2.

[Insert Figures 1, 2 and 3 around here]

As historical transition matrix, we use Moody's average one-year senior rating transition matrix for corporate bond issuers, estimated over the period from 1983 to 2001 [Cantor, Hamilton and $\mathrm{Ou}, 2002]$.

Finally, euro swap rates are downloaded from Bloomberg. We apply a standard bootstrapping procedure to extract zero-coupon rates and interpolate linearly between the available maturities to get a curve for all required maturities. 


\section{Results}

\subsection{Step-Up Bond Values and Step-Up Premiums}

In this section, we analyze the results from the implementation of the framework from Section 3 on the five step-up bonds in Table 3. We define the pricing error of a step-up bond as its market price minus its theoretical value. Specifically, $\mathrm{PE}_{b t}^{i}$ is the pricing error of bond $b$ at day $t$, if method $i$ is used to calculate the theoretical value, $i \in\{E P V, J L T, H\}$. Further, $\operatorname{APE}_{b t}^{i}$ denotes the absolute pricing error for the three methods. The sample means of these six statistics are denoted by $\mathrm{MPE}_{b}^{i}$ and $\mathrm{MAPE}_{b}^{i}$. A negative (positive) sign of an MPE statistic indicates that theoretical values are, on average, too large (small). To test if this over- or underestimation of step-up bond prices is significant for method $i$, we apply a one-sample Z-test (see, e.g., Arnold [1990, Chapter 11])

$$
Z_{b}^{i}=\sqrt{N_{b}} \frac{\mathrm{MPE}_{b}^{i}}{S_{b}^{i}}
$$

where $S_{b}^{i}$ is the sample standard deviation of the $\mathrm{PE}_{b t}^{i}$ series and $N_{b}$ is the sample size for bond b. Asymptotically, $Z_{b}^{i}$ has a standard normal distribution. Similarly, in order to determine if significant performance differences exist between the three methods, we also use a paired Z-test [Arnold, 1990, Chapter 11]. This test tells us whether two time series have the same mean, while allowing for non-zero correlation and unequal variances. The test statistic to compare measures $i$ and $j$ is defined as

$$
Z_{b}^{i j}=\sqrt{N_{b}} \frac{M_{b}^{i j}}{S_{b}^{i j}},
$$

where $M_{b}^{i j}$ and $S_{b}^{i j}$ are the sample mean and sample standard deviation, respectively, of $D_{b t}^{i j}:=$ $\mathrm{APE}_{b t}^{i}-\mathrm{APE}_{b t}^{j}, i, j \in\{E P V, J L T, H\}, i \neq j, t=1, \ldots, N_{b}$. Asymptotically, $Z_{b}^{i j}$ also has a 
standard normal distribution.

Table 4 shows the MPE and MAPE statistics for the telecom step-up bond values generated by the three valuation methods and, for comparison, also the MAPE values for the plain vanilla bonds that are used in the estimation of the issuer-specific survival probability curves. ${ }^{4}$ The paired $Z$-tests are presented in Table 5 for all combinations of the three valuation methods. Further, as an alternative test of the performance of our three methods, we calculate in Table 6 the percentage of days that the market price of a step-up bond lies between the $95 \%$ confidence bounds of the calculated theoretical values. This tells us how uncertainty in the estimated survival probability curves translates into uncertainty in the calculated theoretical step-up bond values.

[Insert Tables 4, 5 and 6 around here]

We also zoom in on the value of the step-up feature. We define the market premium of the step-up feature as the step-up bond's market price minus the value of the equivalent plain vanilla bond. Similarly, we calculate the JLT premium (respectively the historical premium) of the step-up feature as the JLT (respectively the historical) value of the step-up bond minus the value of the equivalent plain vanilla bond. By subtracting the value of the equivalent plain vanilla bond, we 'correct' the market, JLT and historical values for all bond characteristics except for the step-up feature. So, we assume that the step-up feature fully determines the remainder and no other factors are of importance. In addition to the premium, the 95\%-confidence interval around the premium is calculated using the confidence bounds of the equivalent plain vanilla bond. Similar to the pricing errors introduced for the step-up bond prices, we look at the differences between the market step-up premium and the JLT and historical premiums. Since all three figures contain the value of the equivalent plain vanilla bond as correction term, the last four columns in Table 4 and the last column in Table 5 also apply to the step-up premium. Yet Table 6 does not pertain to the step-up premium; the coverage percentages for step-up 
premiums are very similar to those for the step-up bond prices, are therefore omitted.

\section{Deutsche Telecom}

We now discuss the results for each telecom company, beginning with Deutsche Telecom. The MPE values in Table 4 tell that the EPV method typically undervalues and the JLT and historical methods usually overvalue the 2005-bond. The JLT model has the smallest bias to the market price, since both $\mathrm{MPE}^{E P V}$ and $\mathrm{MPE}^{H}$ differ more from zero than $\mathrm{MPE}^{J L T}$, despite that all three MPEs are statistically different from zero. The percentages in Table 6 also show that the JLT model better approximates the step-up market price than the EPV and historical methods. Although the bond values vary between methods, the paired $Z$-test in Table 5 shows that these differences are small and in case of the difference between the EPV and JLT methods not even statistically significant.

Figure 4 shows the market, JLT and historical step-up premiums and the 95\%-confidence bounds around the market premium for the 2005-Deutsche Telecom bond. ${ }^{5}$ Both the JLT and historical premiums are positive and more or less constant, except for a small increase caused by Moody's downgrade of Deutsche Telecom on 13 June 2001; the historical premiums are larger than the JLT premiums. In contrast, the market premiums are much more volatile and sometimes even negative. ${ }^{6}$ A negative market premium for the step-up feature is counterintuitive: as long as the step-up has not been triggered yet, the coupon cannot decrease and hence the step-up feature must have a positive value. From the confidence bounds, however, if follows that the negative market premiums are not statistically significant. The market premium fluctuates mostly between 0 and 1, except in August 2001, where it is above 1 and in November and December 2001, where it is below 0 .

[Insert Figure 4 around here]

For the 2010-bond, the MPE values in Table 4 for the JLT and historical methods are 
relatively small, whereas for the EPV method the MPE value is much larger. Further, all three valuation methods give statistically significant different values at a confidence level of $95 \%$ according to Table 5. Table 6 also displays that the highest coverage percentages are generated by the JLT model.

The market step-up premium of the 2010-bond displays an even more volatile pattern than of the 2005-bond, see Figure 5. This makes sense, because due to its longer maturity, more coupons are affected by the step-up language. During the first half of the analyzed period, until October 2001, the market premium is larger than the JLT and historical premiums, later this pattern is reversed. The market step-up premium becomes negative in December 2001 and January 2002, but like above, the negative market premium is not significant. Both JLT and historical premiums remain roughly constant during the entire period.

[Insert Figure 5 around here]

\section{France Telecom}

Next, we look at the two France Telecom step-up bonds. For the 2004-bond, the MPE and MAPE values for the EPV method in Table 4 approximate the market prices better than the JLT and historical methods. Apparently, the market values this bond as a plain vanilla bond. Also, from Table 6, we observe that the $95 \%$ confidence bounds of the EPV values enclose the market prices in $90 \%$ of the days, and the JLT and historical methods only $85 \%$ and $72 \%$, respectively. Again, Table 5 exhibits that the approximations produced by the three valuation methods differ significantly.

Figure 6 displays the market step-up premium with its 95\%-confidence bounds and the JLT and historical premiums. The same pattern as with Deutsche Telecom emerges, with volatile, though insignificant, market premiums and steady JLT and historical premiums. Also, there is a large drop in both theoretical premiums on 26 September 2001 after the downgrade by 
Moody's from A3 to Baa1. This downgrade triggered the step-up feature (see Table 3), so that the remaining number of step-ups is lower than the number of step-ups at issuance and the coupon can also step down as the rating improves again. The consequence is a decrease in the theoretical step-up premiums, as observed in Figure 6.

\section{[Insert Figure 6 around here]}

For the 2008-France Telecom bond, the MPE value is (in absolute value) equal to the MAPE value for both the JLT and historical methods, see Table 4. This means that both methods always overestimate the market price. The MPE value for the EPV method is the smallest, but there is still a large bias. The confidence bounds statistics in Table 6 reveal that in $48 \%$ of the days the market price and EPV value are statistically indistinguishable, while the confidence bounds of the JLT and historical methods almost never include the market price. The paired $Z$-tests also indicate that the JLT and historical values do not vary much, but that they both differ to a great extent from the EPV values.

As Figure 7 shows, the market premium of the step-up feature of the 2008-bond is again volatile and is even significantly negative during the first few months and also after the downgrade. In contrast, both the JLT and historical premiums remain positive during the full period, also after the downgrade, where their values drop as well. As above, we observe that the JLT and historical premiums are typically larger than the market premium and this difference is quite large, because they virtually never lie within the market premium's confidence bounds.

[Insert Figure 7 around here]

\section{KPN}

Finally, we analyze the 2006-KPN step-up bond. Again the MPE value of the EPV method is closest to zero, though it is significantly smaller than zero, see Table 4 . The JLT model also 
typically overvalues the market price, and the historical method even more, as evidenced by their negative MPE values. The same ranking of the three methods emerges from Table 6 , since in $82 \%$ of the cases the market price lies within the EPV confidence bounds, while for the JLT and historical methods this is $76 \%$ and $33 \%$. Therefore, the market seems to value this bond as a plain vanilla bond.

Finally, we calculate the market, JLT and historical step-up premiums, see Figure 8. Similar to the two France Telecom bonds above, the JLT and historical premiums are less volatile and higher than the market premium, but the premiums of the JLT model often lie within the 95\%confidence bounds. The jump in the JLT and historical premiums and the spike in the market premium on 6 September 2001 follow from Moody's rating downgrade from Baa2 to Baa3. The market premium first shows a dramatic fall and an impressive recovery in the subsequent months after this downgrade and becomes significantly positive and then falls for the second time and becomes negative. Also the JLT premium drops after the downgrade and becomes virtually equal to zero. A different pattern can be observed for the historical method, since it rises following the downgrade and drops at the same time the market premium declines and gradually moves to zero. Again the historical premium is almost always larger than the market premium, something we also noticed for the Deutsche Telecom and France Telecom step-up bonds.

$$
\text { [Insert Figure } 8 \text { around here] }
$$

\section{Recovery Rate}

The step-up bond values constructed by the EPV, JLT and historical methods all use a recovery rate of $50 \%$. However, the 'true' recovery rate for these three Telecom issuers is not known exactly, in fact this is the case for all corporate issuers that have not experienced default. So, we analyze here how sensitive the mean absolute pricing errors (MAPEs) are to variations in the recovery rate in the range from $30 \%$ to $70 \%$. Figure 9 shows that for the 2005-Deutsche Telecom 
bond, the MAPE values produced by the historical and EPV valuation methods always increase whereas the MAPEs associated with the JLT valuation method always decrease as the recovery rate increases. In contrast, for the 2010-Deutsche Telecom bond, both MAPEs and recovery rate always move in the same direction, the same applies for the 2004-France Telecom bond. The MAPEs generated by the historical valuation method rise as the recovery rate becomes larger for both the 2008-France Telecom and the 2006-KPN bond. The opposite pattern can be observed for the MAPEs associated with the JLT and EPV valuation methods, with the exception of the MAPEs of the 2006-KPN bond that increases again at the $70 \%$ recovery rate.

We can observe that for three of the five step-up bonds, i.e. the 2010-Deutsche Telecom and both France Telecom bonds, the order of the valuation methods is always the same, irrespective of the value of the recovery rate. For the other two bonds, the 2005-Deutsche Telecom bond and the 2006-KPN bond, the historical method always performs worst, but the JLT and EPV methods cross at a recovery rate of $50 \%$ and $70 \%$, respectively; for smaller values, the EPV method is better, whereas for larger values the JLT method yields smaller errors.

[Insert Figure 9 around here]

\subsection{Step-Up Protection}

\section{Volatility Analysis}

We now analyze the protection a step-up provision offers to an investor. We hypothesize that the price volatility of the step-up bond is lower than the volatility of its equivalent plain vanilla bond, because the step-up feature compensates a lower rating with a higher coupon, and vice versa, see also McAdie et al. [2000]. ${ }^{7}$ So, the step-up feature should work as a cushion against rating migrations.

We compare the variance of a step-up bond's market prices, $\sigma_{\text {step-up }}^{2}$, with the variance of 
its equivalent plain vanilla bond's values, $\sigma_{E P V}^{2}$. The null hypothesis

$$
H_{0}: \frac{\sigma_{\text {step-up }}^{2}}{\sigma_{E P V}^{2}}=1
$$

is tested using the test statistic

$$
V=\frac{S_{s t e p-u p}^{2}}{S_{E P V}^{2}}
$$

where $S_{\text {step-up }}^{2}$ and $S_{E P V}^{2}$ are the sample variances of the step-up bond market prices and equivalent plain vanilla bond values, respectively. $V$ follows an $F$-distribution with $n_{\text {step-up }}-1$ and $n_{E P V}-1$ degrees of freedom, where $n_{i}$ equals the number of $i$-observations, with $i \in$ \{step-up, EPV\}, see e.g. Madsen and Moeschenberger [1986].

Table 7 shows that the outcome of this test statistic is equivocal. The null hypothesis is easily rejected at the $95 \%$ confidence level for both the 2005-and 2010-Deutsche Telecom bonds and the 2008-France Telecom bond. So, for these three bonds the step-up bond price variance is lower than the variance of the equivalent plain vanilla bond. ${ }^{8}$ For the 2004-France Telecom and the 2006-KPN bonds, the two variances are statistically indistinguishable.

[Insert Table 7 around here]

\section{Event Analysis}

Next, we carry out an event analysis to test the protection a step-up bond offers in case of rating (outlook) downgrades. As long as the timing and/or size of a rating downgrade or negative outlook change are not fully anticipated by the market, plain vanilla bonds have a negative return on the event date, see e.g. Hand, Holthausen and Leftwich [1992]. Since a step-up bond compensates investors for the decreased creditworthiness via a higher coupon, we hypothesize that it has a higher return than its equivalent plain vanilla bond. 
To test this hypothesis, we define the excess step-up return as the step-up bond market return minus the return of its equivalent plain vanilla bond; so, the step-up bond return is fully corrected for all bond characteristics except for the step-up language. We first calculate the excess return $E R_{i t}$ for bond $i$ for the event day, $t=0$, and the three succeeding trading days, $t=1,2,3$. Then, we calculate the average $E R_{t}$ of these excess returns for each day over the five step-up bonds. We also consider cumulative excess returns, defined as

$$
C E R_{i t}=\sum_{s=0}^{t} E R_{i s}
$$

and their averages $C E R_{t}$. We test the significance of the average excess returns and the cumulative average excess returns using simple $t$-tests as described in Ritter [1991]. If both Moody's and S\&P's change their rating (outlook) of the same company at the same time, we treat this as a single event. Furthermore, if a rating action occurs within three trading days of an earlier rating action, we delete this rating action from the analysis.

Table 8 shows the results of this event analysis. On the event date, the return on the EPV bond is indeed negative, as expected. Howerver, the return on the step-up bond is even more negative, so that the excess step-up return is negative. Although this negative excess return is not significant, it does not conform with our expectations. During the post event period, the average excess return becomes positive, but stays statistically insignificant. The cumulative excess returns are always negative and insignificant for the whole post event period.

Therefore, contrary to our expectations, the step-up feature does not offer investors positive excess returns in case of a rating downgrade or a negative outlook, but instead offers statistically identical returns as the EPV bond.

[Insert Table 8 around here] 


\section{Summary}

European telecom companies have issued rating-triggered step-up coupon bonds in order to compensate bond investors for losses in the event of rating downgrades. The coupon of such a step-up bond depends on its issuer rating or the rating of the issuer's long term debt. If this rating deteriorates and hits a predefined level, the step-up coupon is triggered and the coupon rises with a predefined number of basis points. We apply risk-neutral transition probabilities using the Jarrow, Lando and Turnbull [1997, JLT] framework to value these rating-triggered stepup bonds. For comparison purposes, we also value step-up bonds using historical probabilities and as plain vanilla bonds comparable to step-up bonds except for the step-up feature. Further we demonstrate our results over a long time period. Next, we test the volatility of a step-up bond versus the equivalent plain vanilla bond and we perform a rating and outlook change event analysis of excess step-up bond returns.

We find that the market seems to value the Deutsche Telecom step-up bonds, whose coupons make a single step-up after the rating hits the trigger level, according to the JLT model. On the other hand, for the France Telecom and KPN step-up bonds, whose coupons step up every time a rating hits a trigger level, the market seems to resort to valuation as plain vanilla bonds. Further, we find that the market premiums of the step-up feature are much more volatile than the JLT and historical premiums. These theoretical premiums are stable, except for changes caused by downgrades. Further, the JLT model approximates the market premiums always better than the historical valuation method.

From the five step-up bonds, the two Deutsche Telecom bonds and the 2008-France Telecom bond have a significantly lower price volatility than their equivalent plain vanilla bonds at a 95\% confidence level. So, these three step-up bonds offer protection in terms of a lower price volatility. The volatilities of the 2004-France Telecom and the KPN step-up bond are statistically indistinguishable from their equivalent plain vanilla bonds. Therefore, these step-up bonds do 
not offer a cushion against rating migrations in the form of dampened price movements. The results from the event analysis, another way of looking at the step-up protection, demonstrate that step-up bonds do not offer superior returns to an investor in case of rating downgrades or negative outlooks. 


\section{References}

Acharya, V., Das, S. R. and Sundaram, R. [2002], 'A discrete-time approach to no-arbitrage pricing of credit derivatives with rating transitions', Financial Analysts Journal (MayJune), 28-44.

Arnold, S. F. [1990], Mathematical Statistics, Prentice Hall, New Jersey.

Arvanitis, A., Gregory, J. and Laurent, J.-P. [1999], 'Building models for credit spreads', The Journal of Derivatives (Spring), 27-43.

Bielecki, T. R. and Rutkowski, M. [2000], 'Multiple ratings model of defaultable term structure', Mathematical Finance 10(2), 125-139.

Brown, P. J. [1994], Constructing \& calculating bond indices, a guide to the EFFAS standardized rules, Cambridge University Press, Cambridge.

Cantor, R., Hamilton, D. and Ou, S. [2002], Default \& recovery rates of corporate bond issuers, a statistical review of Moody's ratings performance 1970-2001, Global Credit Research, Moody's Investors Service.

Conroy, P. [2000], 'Valuing ratings-sensitive coupon language', Credit (July), 62-64.

Das, S. R. and Tufano, P. [1996], 'Pricing credit-sensitive debt when interest rates, credit ratings and credit spreads are stochastic', Journal of Financial Engineering 5, 161-198.

Fumagalli, R. and Tauren, M. [2001], Valuing bonds with step-up coupons, European Credit Research, Credit Strategy, Schroder Salomon Smith Barney.

Hand, J. R., Holthausen, R. W. and Leftwich, R. W. [1992], 'The effect of bond rating agency announcements on bond and stock prices', Journal of Finance 47(2), 733-752.

Heath, D., Jarrow, R. A. and Morton, A. [1992], 'Bond pricing and the term structure of interest rates: A new methodology', Econometrica 60(1), 77-105. 
Houweling, P., Mentink, A. and Vorst, T. [2003], How to measure corporate bond liquidity?, Working paper, Erasmus University Rotterdam, http://www.few.eur.nl/few/people/houweling/.

Houweling, P. and Vorst, T. [2002], An empirical comparison of default swap pricing models, Working paper, Erasmus University Rotterdam, http://www.few.eur.nl/few/people/houweling/.

Israel, R. B., Rosenthal, J. S. and Wei, J. Z. [2001], 'Finding generators for Markov chains via empirical transition matrices, with applications to credit ratings', Mathematical Finance 11(2), 245-265.

Jarrow, R. A., Lando, D. and Turnbull, S. M. [1997], 'A Markov model for the term structure of credit spreads', Review of Financial Studies 10(2), 481-523.

Jarrow, R. A. and Turnbull, S. M. [2000], 'The intersection of market and credit risk', Journal of Banking \& Finance 24, 271-299.

Kijima, M. and Komoribayashi, K. [1998], 'A Markov chain model for valuing credit risk derivatives', The Journal of Derivatives (Fall), 97-108.

Lando, D. [1998], 'On Cox processes and credit risky securities', Review of Derivatives Research 2, 99-120.

Madsen, R. W. and Moeschenberger, M. L. [1986], Statistical Concepts - with Applications to Business and Economics, 2nd edn, Prentice Hall, New Jersey.

Marchakitus, S., Soderberg, M. and Bramley, A. [2001], European telecoms update, watch your step..., Credit Research Sector Report, J.P. Morgan Securities Ltd.

McAdie, R., Martin, S. and O'Kane, D. [2000], Credit-sensitive telecom bonds: A framework for valuation, European Credit Strategy \& Research Market Analysis, Lehman Brothers. 
Nagpal, K. M. and Bahar, R. [2000], 'Modelling the dynamics of rating transition', Credit (March).

Ritter, J. R. [1991], 'The long-run performance of initial public offerings', Journal of Finance 46(1), 3-27.

Schönbucher, P. J. [2000], A LIBOR market model with default risk, Working paper, University of Bonn, http://www.schonbucher.de/.

Sirinathsingh, M. [2001], Valuing rating-triggered step-up bonds, Fixed Income Strategy, J.P. Morgan Securities Inc.

Turc, J. [2001], A rule-of-thumb for valuing telecom coupon step-ups, Quantitative strategy, Euro Credit Monthly, Société General. 


\section{Notes}

${ }^{1}$ Usually, Moody's and S\&P report (multiples of) 1-year transition matrices. However, the time between the valuation day and coupon and redemption dates equals almost never exactly (multiples of) one year. Therefore, we adjust the historical transition matrix and make it maturity-dependent using a generator matrix, as described by Israel, Rosenthal and Wei [2001].

${ }^{2}$ Fumagalli and Tauren [2001] assume that a rating action of one agency is followed by the other agency in the next six months.

${ }^{3}$ Note that the summation may be reduced from $K$ terms to $K-1$ terms, since the $K^{\text {th }}$ term is zero: $\tilde{\mathbb{P}}_{t}\left(\tau>t_{j} \wedge R_{t_{j-1}}=K\right)=0$.

${ }^{4}$ Note that per definition MPE for the plain vanilla bonds is zero, since the pricing error for a plain vanilla bond is simply its residual from the least squares estimation of the survival probability curve.

${ }^{5}$ Due to a lack of plain vanilla Deutsche Telecom bonds prior to 14 May 2001, its figures start well after the step-up bond's issue date 6 July 2000.

${ }^{6}$ Lehman Brothers [McAdie et al., 2000] also find a negative value in their analysis of euro step-up bonds on 13 July 2000.

${ }^{7}$ Also, Olivetti/Tecnost's Chief Financial Officer, after linking the coupons of its bonds to its credit rating, stated: "we think having these sort of volatility protection measures associated with our bonds should result in a lower capital cost" (Bloomberg Equity News, June 16, 2000, quoted in Acharya et al. [2002, footnote 9]).

${ }^{8}$ If the step-up bonds were less liquid than the plain vanilla bonds, then this outcome could be explained by the occurrence of stale prices. However, the step-up bonds are probably more liquid than the plain vanilla bonds, because they are younger and have larger notionals than the latter, see e.g. Houweling, Mentink and Vorst [2003] and the references therein. 


\begin{tabular}{|c|c|c|c|c|c|}
\hline Type & Step-up & Step-down & One-off & And/or & Accrual \\
\hline $\mathbf{A}$ & $\checkmark$ & $\checkmark$ & & or & next \\
\hline B & $\checkmark$ & $\checkmark$ & $\checkmark$ & and & next \\
\hline $\mathrm{C}$ & $\checkmark$ & & $\checkmark$ & or & immediately \\
\hline
\end{tabular}

Table 1. Step-up bond types.

Description of the three step-up bond types. Step-up: the coupon increases if the rating decreases and hits the rating-trigger. Step-down: the coupon decreases if the rating increases again. One-off: the coupon increases only once, even if the rating falls further below the rating-trigger; for bonds that are not one-off, each further decrease in the rating, causes a further increase in the coupon. And/or: determines whether the coupon is adjusted if Moody's and S\&P adjust their ratings, or if Moody's or S\&P adjusts its rating. Accrual: determines the date at which the adjusted coupon starts accruing: immediately following a rating action, or on the next coupon date after the rating action. 


\begin{tabular}{lccc}
\hline \hline & All bonds & Quoted, plain vanilla bonds & Step-up bonds \\
& & & \\
\hline & 5 & 0 & 3 \\
British Telecom Group & 29 & 14 & 2 \\
Deutsche Telecom & 37 & 7 & 2 \\
France Telecom & 10 & 5 & 4 \\
KPN & 12 & 0 & 2 \\
Olivetti SPA/Tecnost & 7 & 2 & \\
Telecom Italia & & & 2 \\
\hline \hline
\end{tabular}

Table 2. Number of bonds.

Total number of euro-(re)denominated, quoted plain vanilla and step-up bonds for all telecom companies. 


\begin{tabular}{lcccc}
\hline \hline & & & & \\
& Maturity & Step-up type & X (bps) & Y (Moody's/S\&P) \\
\hline \multirow{2}{*}{ Deutsche Telecom } & 2005 & B & 50 & Baa1/BBB+ \\
& 2010 & B & 50 & Baa1/BBB+ \\
France Telecom & 2004 & A & 25 & Baa1/BBB+ \\
KPN & 2008 & A & 25 & Baa1/BBB+ \\
& 2006 & A & 37.5 & Baa3/BBB- \\
\hline \hline
\end{tabular}

\section{Table 3. Step-up bond characteristics.}

The main characteristics of the five step-up bonds, where step-up type refers to Table 1 and $X$ and $Y$ represent the number of basis points step-up and the rating-trigger level respectively. 


\begin{tabular}{|c|c|c|c|c|c|c|c|c|}
\hline & \multirow{3}{*}{$\begin{array}{c}\begin{array}{c}\text { Plain } \\
\text { vanillas }\end{array} \\
\text { MAPE }\end{array}$} & \multicolumn{7}{|c|}{ Step-ups } \\
\hline & & \multirow[b]{2}{*}{ Maturity } & \multicolumn{2}{|c|}{ EPV } & \multicolumn{2}{|c|}{ JLT } & \multicolumn{2}{|c|}{ Historical } \\
\hline & & & MPE & MAPE & MPE & MAPE & $\mathrm{MPE}$ & MAPE \\
\hline \multirow[t]{2}{*}{ Deutsche Telecom } & 0.29 & 2005 & $0.15^{*}$ & $0.24^{*}$ & $-0.09^{*}$ & $0.25^{*}$ & $-0.29^{*}$ & $0.36^{*}$ \\
\hline & & 2010 & $1.05^{*}$ & $1.15^{*}$ & $0.20^{*}$ & $0.82^{*}$ & $-0.34^{*}$ & $0.89^{*}$ \\
\hline \multirow[t]{2}{*}{ France Telecom } & 0.64 & 2004 & $-0.26^{*}$ & $0.33^{*}$ & $-0.41^{*}$ & $0.46^{*}$ & $-0.56^{*}$ & $0.57^{*}$ \\
\hline & & 2008 & $-0.87^{*}$ & $0.94^{*}$ & $-1.99^{*}$ & $1.99^{*}$ & $-2.57^{*}$ & $2.57^{*}$ \\
\hline $\mathbf{K P N}$ & 1.09 & 2006 & $-0.44^{*}$ & $1.13^{*}$ & $-0.95^{*}$ & $1.42^{*}$ & $-2.28^{*}$ & $2.29^{*}$ \\
\hline
\end{tabular}

Table 4. Pricing errors.

Mean absolute pricing errors (MAPE) between the market price and the theoretical price of the plain vanilla bonds and both mean pricing errors (MPE) and MAPEs, between the market price and the equivalent plain vanilla (EPV) bond value for the step-up bonds, between the market price and the Jarrow, Lando and Turnbull (1997, JLT) value for the step-up bonds, and between the market price and the historical value for the step-up bonds. An asterisk $\left({ }^{*}\right)$ indicates significance of the one-sample $Z$-test at a $95 \%$ confidence level. 


\begin{tabular}{lcccc}
\hline \hline & & & & \\
& Maturity & EPV - JLT & EPV - Historical & JLT - Historical \\
\hline \multirow{2}{*}{ Deutsche Telecom } & 2005 & 0.00 & $-0.12^{*}$ & $-0.12^{*}$ \\
& 2010 & $0.33^{*}$ & $0.26^{*}$ & $-0.07^{*}$ \\
France Telecom & 2004 & $-0.13^{*}$ & $-0.24^{*}$ & $-0.11^{*}$ \\
& 2008 & $-1.04^{*}$ & $-1.63^{*}$ & $-0.58^{*}$ \\
KPN & 2006 & $-0.30^{*}$ & $-1.16^{*}$ & $-0.86^{*}$ \\
& & & & \\
\hline \hline
\end{tabular}

Table 5. Paired $Z$-tests.

The difference between mean absolute pricing errors (MAPE) of the equivalent plain vanilla (EPV) and Jarrow, Lando and Turnbull (1997, JLT) value for the step-up bonds, the EPV and historical value for the step-up bonds, the JLT bond and historical value for the step-up bonds. An asterisk $\left(^{*}\right)$ indicates significance of the paired-sample $Z$-test at a $95 \%$ confidence level. 


\begin{tabular}{lcccc}
\hline \hline & & & & \\
& Maturity & EPV & JLT & Historical \\
& & & & \\
\hline \multirow{3}{*}{ Deutsche Telecom } & 2005 & $73 \%$ & $85 \%$ & $62 \%$ \\
& 2010 & $33 \%$ & $68 \%$ & $50 \%$ \\
France Telecom & 2004 & $90 \%$ & $85 \%$ & $72 \%$ \\
& 2008 & $48 \%$ & $0 \%$ & $6 \%$ \\
KPN & 2006 & $82 \%$ & $76 \%$ & $33 \%$ \\
& & & & \\
\hline \hline
\end{tabular}

Table 6. Confidence interval coverage percentages.

Percentages of market step-up bond prices that lie between the $95 \%$ upper and lower bounds of equivalent plain vanilla (EPV), Jarrow, Lando and Turnbull (1997, JLT), and historical bond prices. 


\begin{tabular}{lcccc}
\hline \hline & & & & \\
& Maturity & Test statistic & $n$ & $p$-value \\
& & & & \\
\hline \multirow{2}{*}{ Deutsche Telecom } & 2005 & 0.72 & 189 & 0.025 \\
& 2010 & 0.56 & 189 & 0.000 \\
France Telecom & 2004 & 1.04 & 228 & 0.768 \\
& 2008 & 0.75 & 228 & 0.031 \\
KPN & 2006 & 1.00 & 210 & 1.000 \\
& & & & \\
\hline \hline
\end{tabular}

Table 7. Volatility analysis.

$F$-statistics for the null hypothesis that the step-up bonds and their equivalent plain vanilla bonds have equal variances. 


\begin{tabular}{|c|c|c|c|c|c|c|c|c|}
\hline \multirow[b]{2}{*}{ Day } & \multicolumn{4}{|c|}{ Returns } & \multicolumn{4}{|c|}{ Cumulative returns } \\
\hline & Step-up & $\mathrm{EPV}$ & Excess & $t$-value & Step-up & $\mathrm{EPV}$ & Excess & $t$-value \\
\hline 0 & $-1.89 \%$ & $-0.77 \%$ & $-1.12 \%$ & -1.14 & & & & \\
\hline 1 & $0.36 \%$ & $-0.14 \%$ & $0.50 \%$ & 0.65 & $-1.53 \%$ & $-0.90 \%$ & $-0.63 \%$ & -0.97 \\
\hline 2 & $-0.11 \%$ & $-0.61 \%$ & $0.50 \%$ & 1.72 & $-1.64 \%$ & $-1.51 \%$ & $-0.13 \%$ & -0.20 \\
\hline 3 & $0.16 \%$ & $0.18 \%$ & $-0.02 \%$ & -0.15 & $-1.47 \%$ & $-1.32 \%$ & $-0.15 \%$ & -0.23 \\
\hline
\end{tabular}

Table 8. Event analysis.

Average (cumulative) returns for the step-up bonds and their equivalent plain vanilla (EPV) bonds, as well as the excess returns of the former over the latter and their $t$-values, after rating downgrades and negative outlook changes, for the event date and the three succeeding days. 


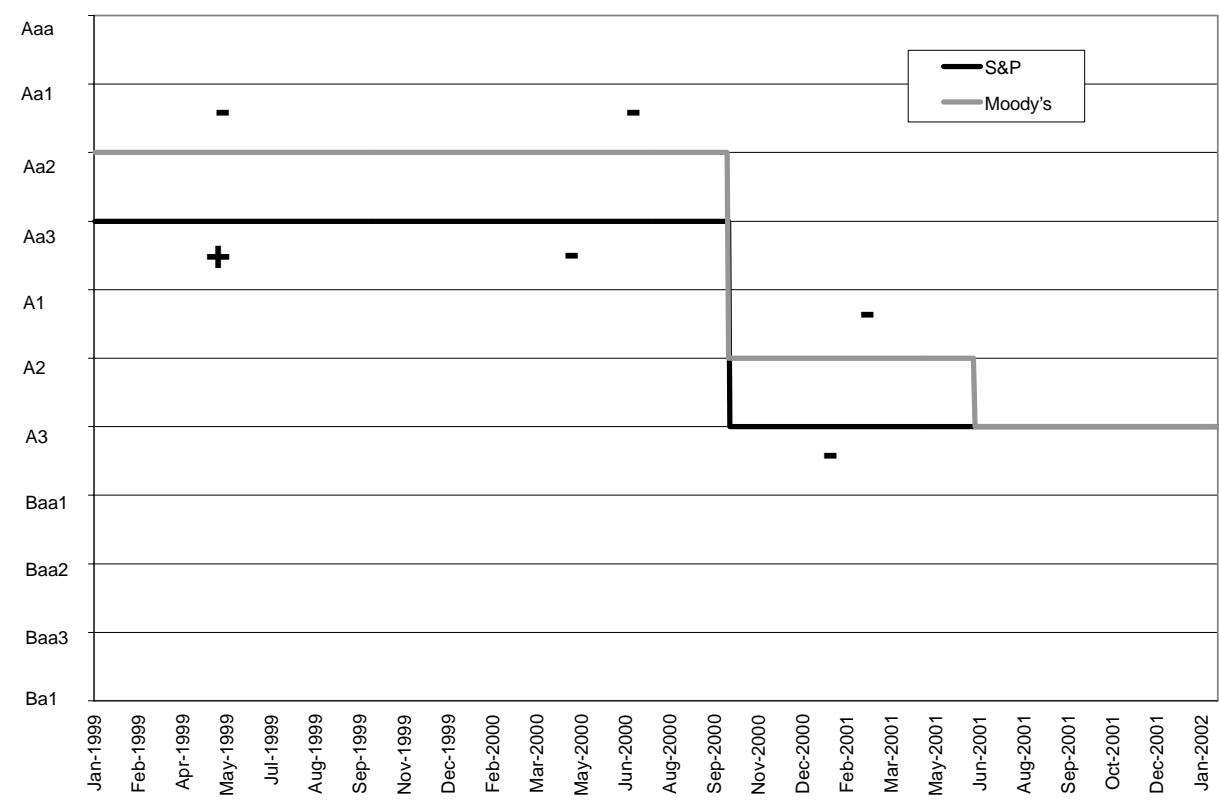

Figure 1. Deutsche Telecom ratings.

Moody's and S\&P's rating and outlook history of Deutsche Telecom. 


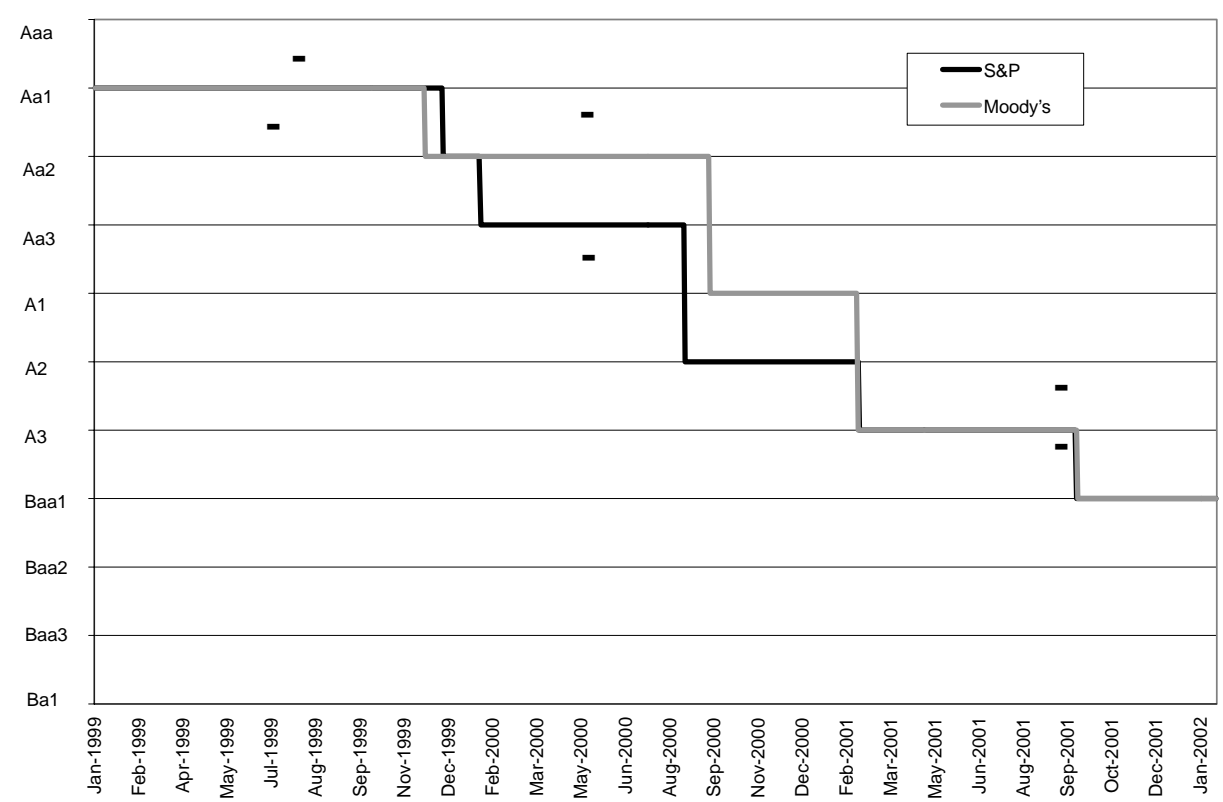

Figure 2. France Telecom ratings.

Moody's and S\&P's rating and outlook history of France Telecom. 


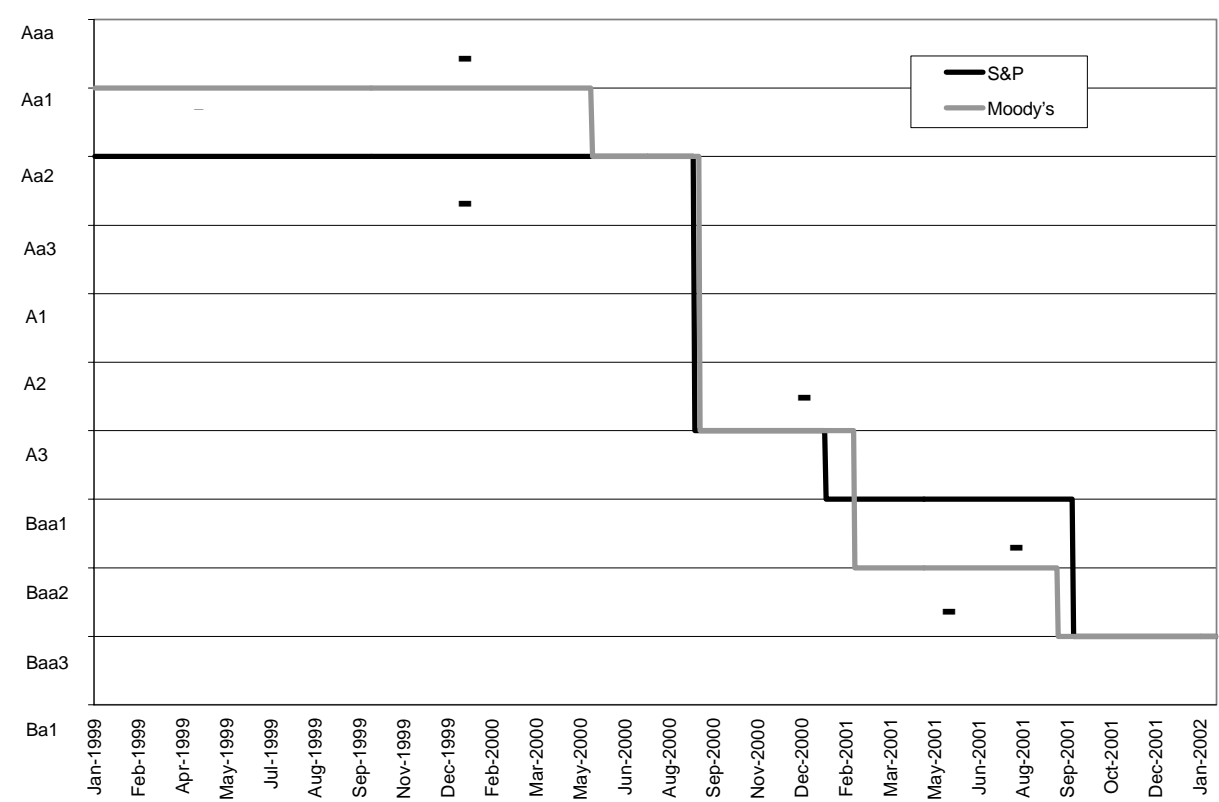

Figure 3. KPN ratings.Moody's and S\&P's rating and outlook history of KPN Telecom. 


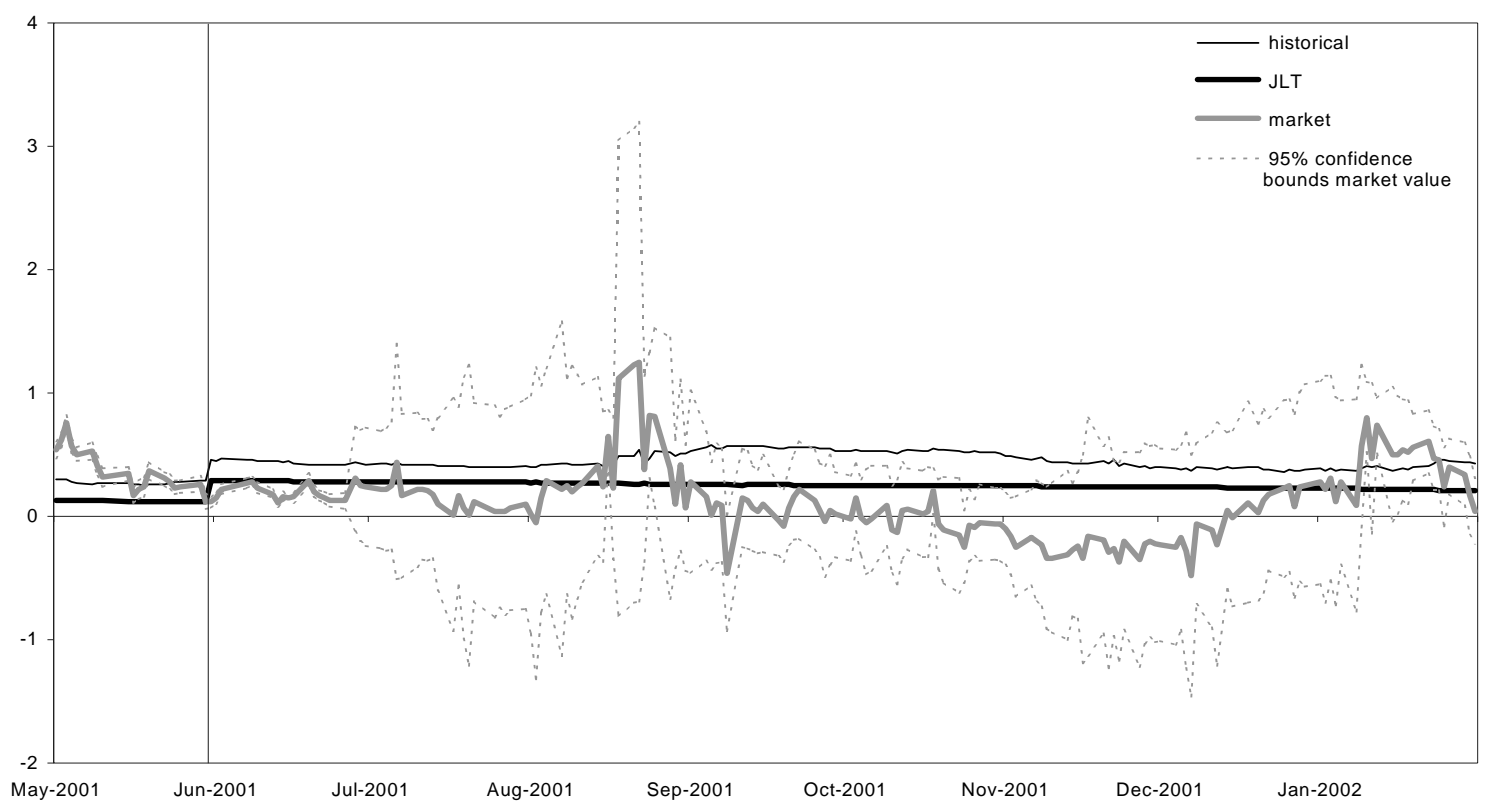

Figure 4. 2005-Deutsche Telecom step-up premiums.

The market, JLT and historical step-up premium of the 2005-Deutsche Telecom step-up bond. The dotted lines are the $95 \%$ confidence bounds of the market premium. The vertical line indicates a rating downgrade by Moody's. 


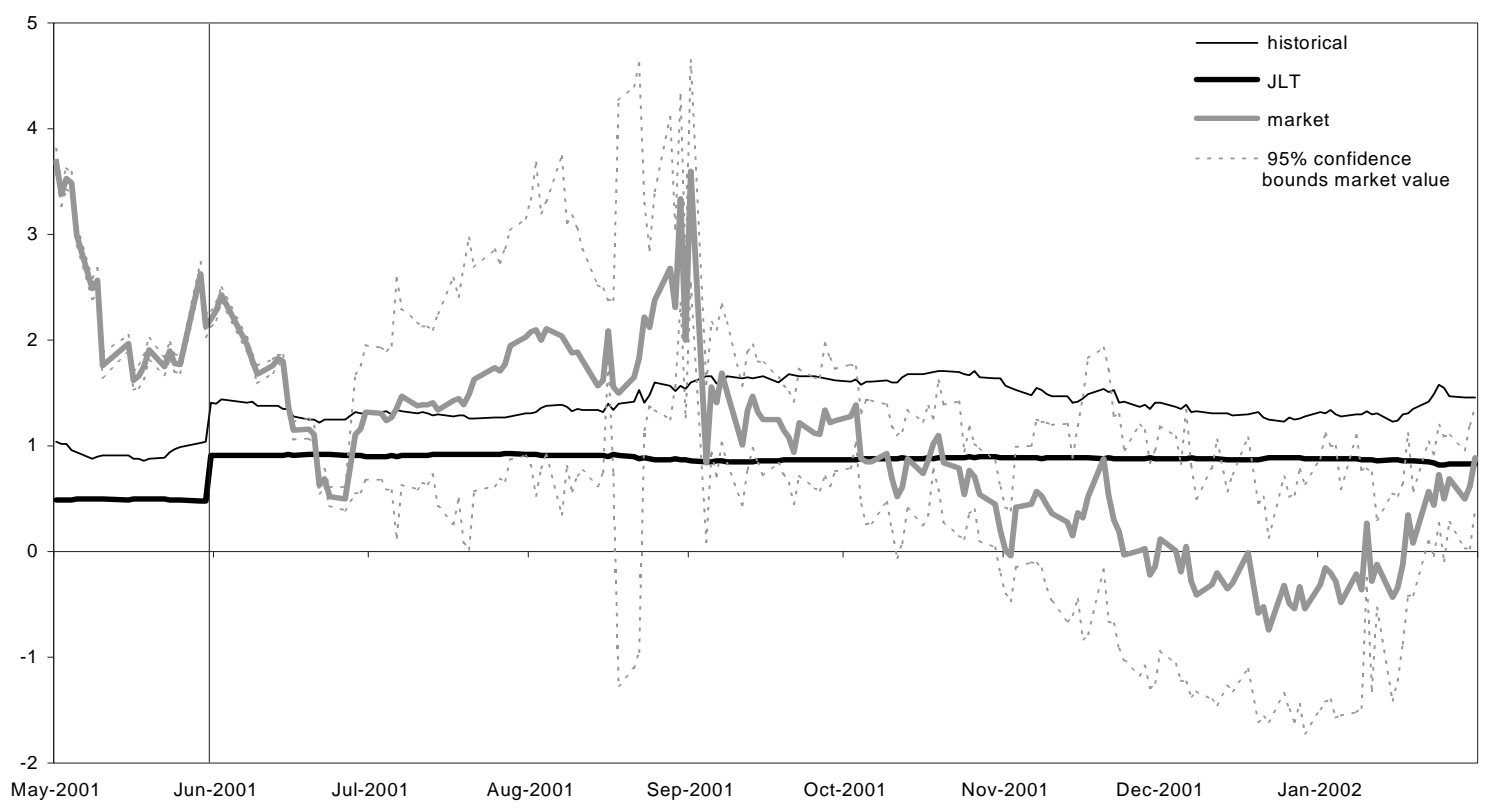

Figure 5. 2010-Deutsche Telecom step-up premiums.

The market, JLT and historical step-up premium of the 2010-Deutsche Telecom step-up bond. The dotted lines are the $95 \%$ confidence bounds of the market premium. The vertical line indicates a rating downgrade by Moody's. 


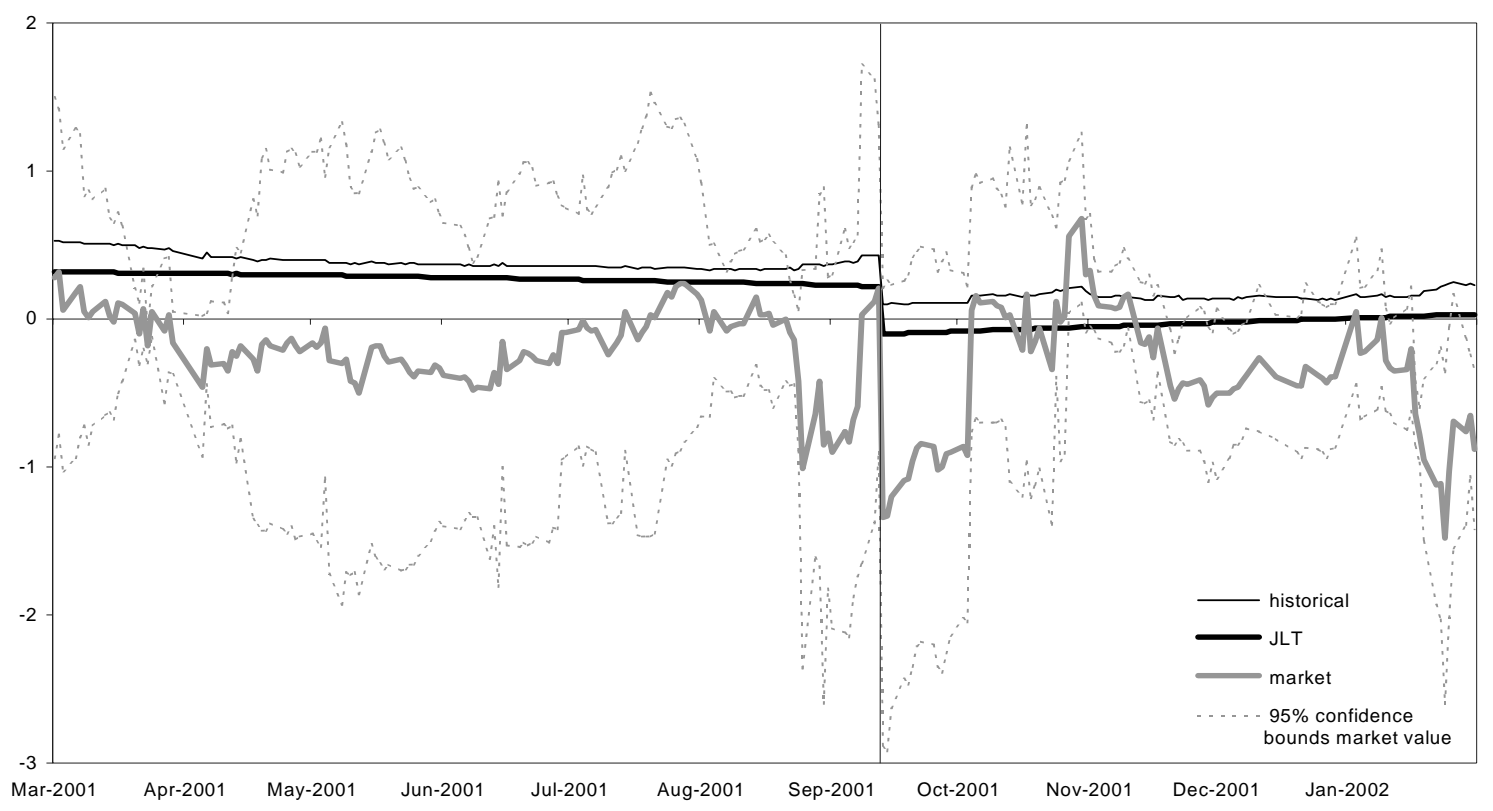

Figure 6. 2004-France Telecom step-up premiums.

The market, JLT and historical step-up premium of the 2004-France Telecom step-up bond. The dotted lines are the $95 \%$ confidence bounds of the market premium. The vertical line indicates a rating downgrade by Moody's. 


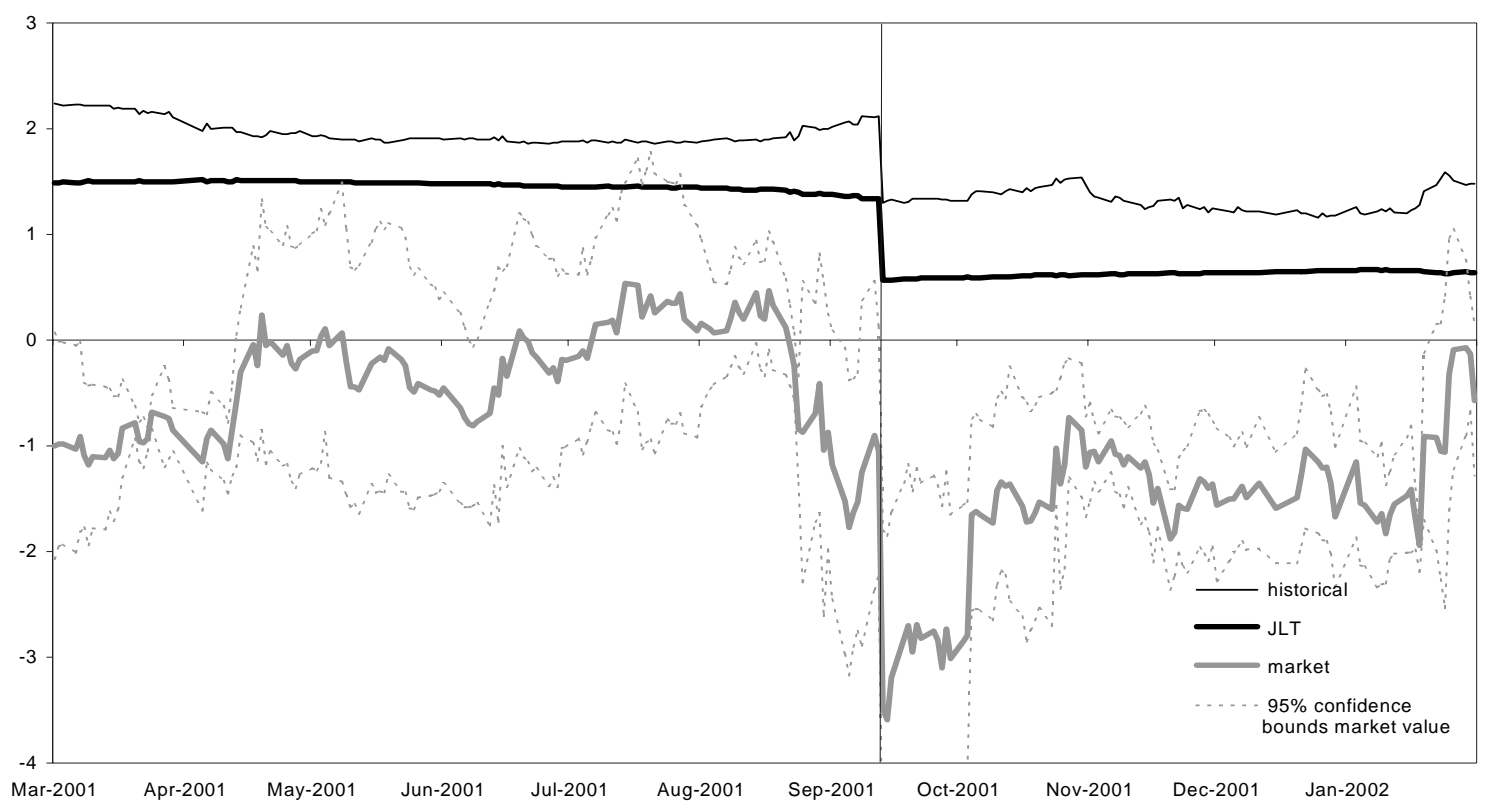

Figure 7. 2008-France Telecom step-up premiums.

The market, JLT and historical step-up premium of the 2008-France Telecom step-up bond. The dotted lines are the $95 \%$ confidence bounds of the market premium. The vertical line indicates a rating downgrade by Moody's. 


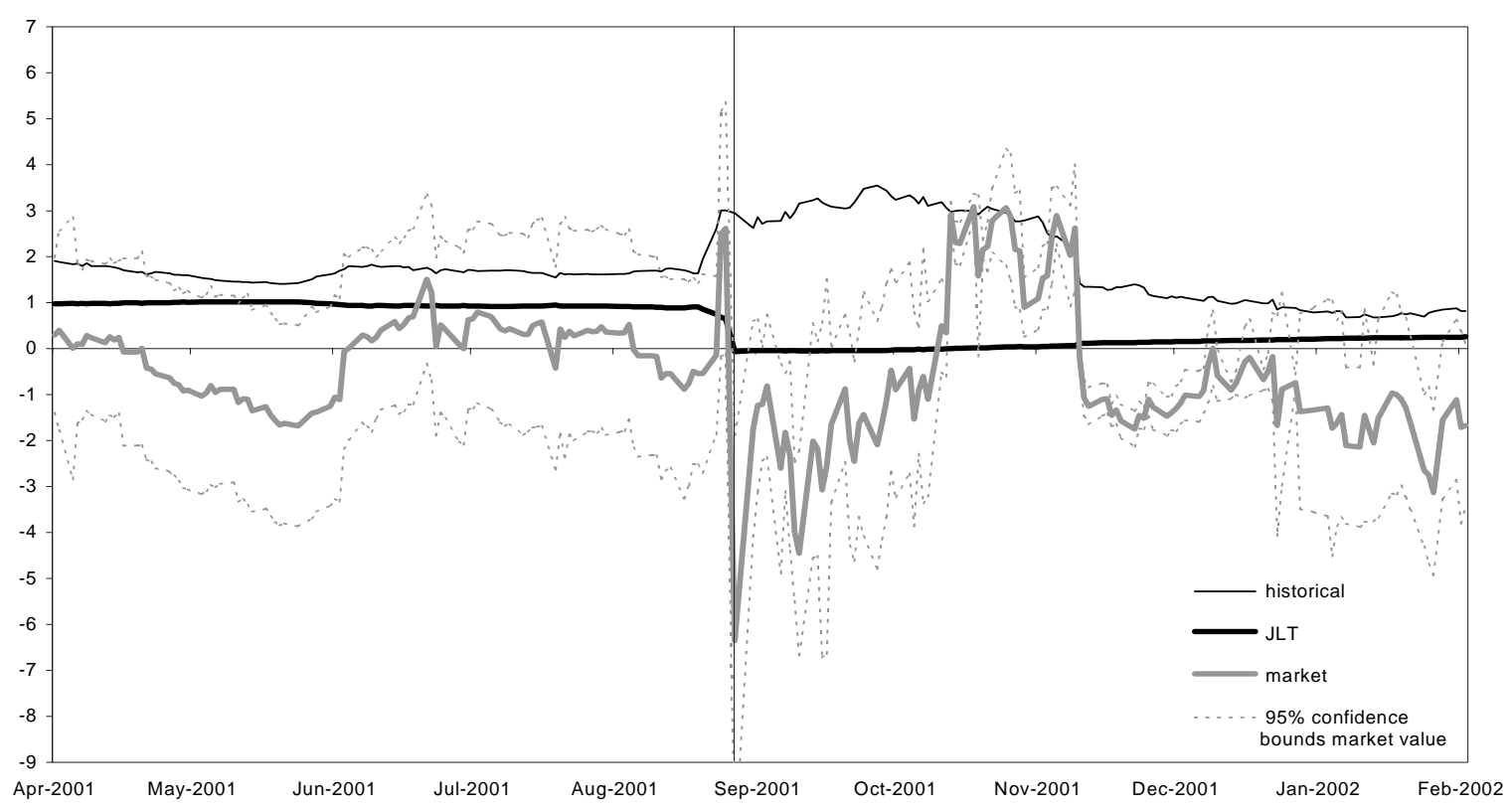

Figure 8. 2006-KPN step-up premiums.

The market, JLT and historical step-up premium of the 2006-KPN step-up bond. The dotted lines are the $95 \%$ confidence bounds of the market premium. The vertical line indicates a rating downgrade by Moody's. 


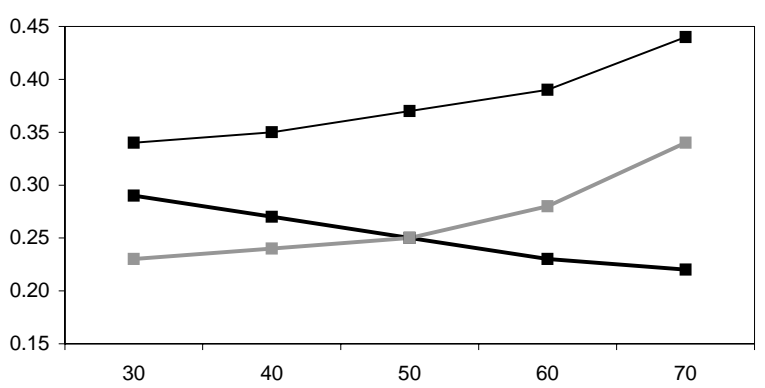

(a)

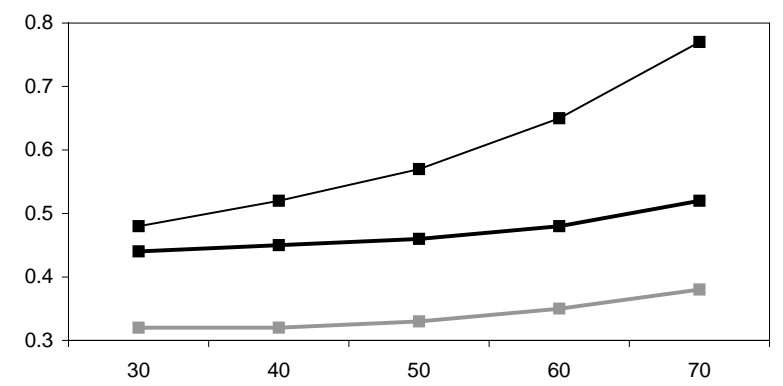

(c)

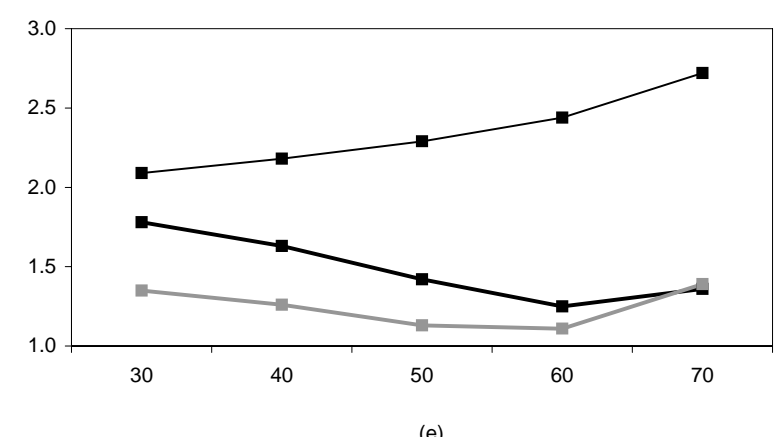

(e)

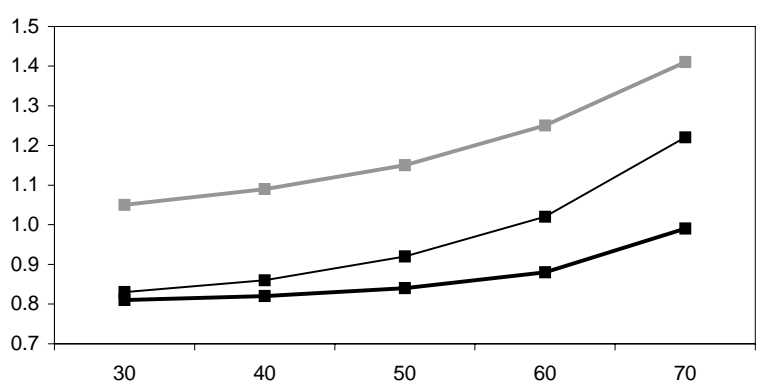

(b)

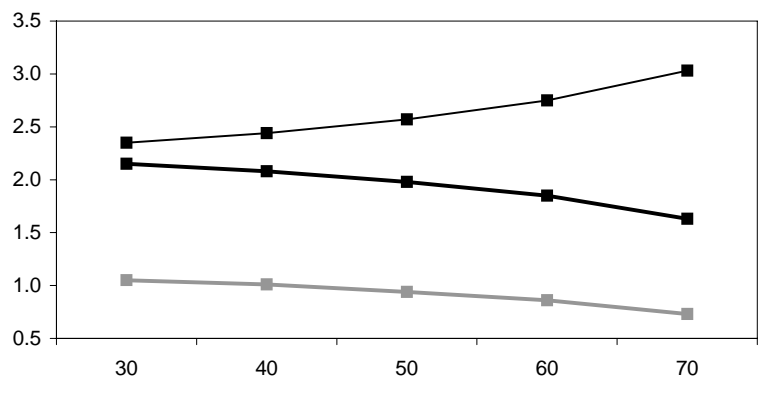

(d)

Figure 9. Recovery rate sensitivity analysis.

The graphs depict the mean absolute pricing errors for various recovery rates, for the equivalent plain vanilla bond (thick grey line), JLT (thick black line) and historical (thin black line) method respectively, for all step-up bonds: (a) 2005-Deutsche Telecom, (b) 2010-Deutsche Telecom, (c) 2004-France Telecom, (d) 2008-France Telecom, and (e) 2006-KPN. 